ХРОНИКА

DOI: $10.17805 /$ trudy.2017.4.10

\title{
МЕЖДУНАРОДНАЯ НАУЧНАЯ ШКОЛА ДЛЯ МОЛОДЕЖИ «БИОТЕХНОЛОГИЧЕСКОЕ УЛУЧШЕНИЕ ЧЕЛОВЕКА КАК ПРОБЛЕМА СОЦИАЛЬНО-ГУМАНИТАРНОГО ЗНАНИЯ»
}

\author{
В. А. Луков, С. В. Луков \\ Московский гуманитарный университет
}

Аннотация: Дан краткий обзор работы Международной научной школы для молодежи «Биотехнологическое улучшение человека как проблема социально-гуманитарного знания», проходивщей в Московском гуманитарном университете 26-30 июня 2017 г.

Ключевые слова: научная школа; молодежь; биотехнологии; улучшение человека; Московский гуманитарный университет; проблемы биоэтики; обзор

\section{INTERNATIONAL SCIENTIFIC SCHOOL FOR YOUNG PEOPLE: “BIOTECHNOLOGICAL ENHANCEMENT OF THE HUMAN AS AN ISSUE OF SOCIAL AND HUMANITARIAN KNOWLEDGE” \\ Val. A. Lukov, S. V. Lukov \\ Moscow University for the Humanities}

Abstract: The paper gives a brief review of the work of the International Scientific School for Young People "Biotechnological Enhancement of the Human as an Issue of Social and Humanitarian Knowledge", which was held at Moscow University for the Humanities on June 26-30, 2017.

Keywords: scientific school for Young People; biotechnologies; human enhancement; Moscow University for the Humanities; issues of bioethics; review

26-30 июня 2017 г. в Московском гуманитарном университете состоялась Международная научная школа для молодежи «Биотехнологическое улучшение человека как проблема социально-гуманитарного знания», организованная Московским гуманитарным университетом и Институтом философии РАН в рамках проекта, осуществляемого под руководством члена-корреспондента РАН Б. Г. Юдина при поддержке гранта РНФ 15-18-30057 «Гуманитарный анализ биотехнологических проектов «улучшения" человека». 


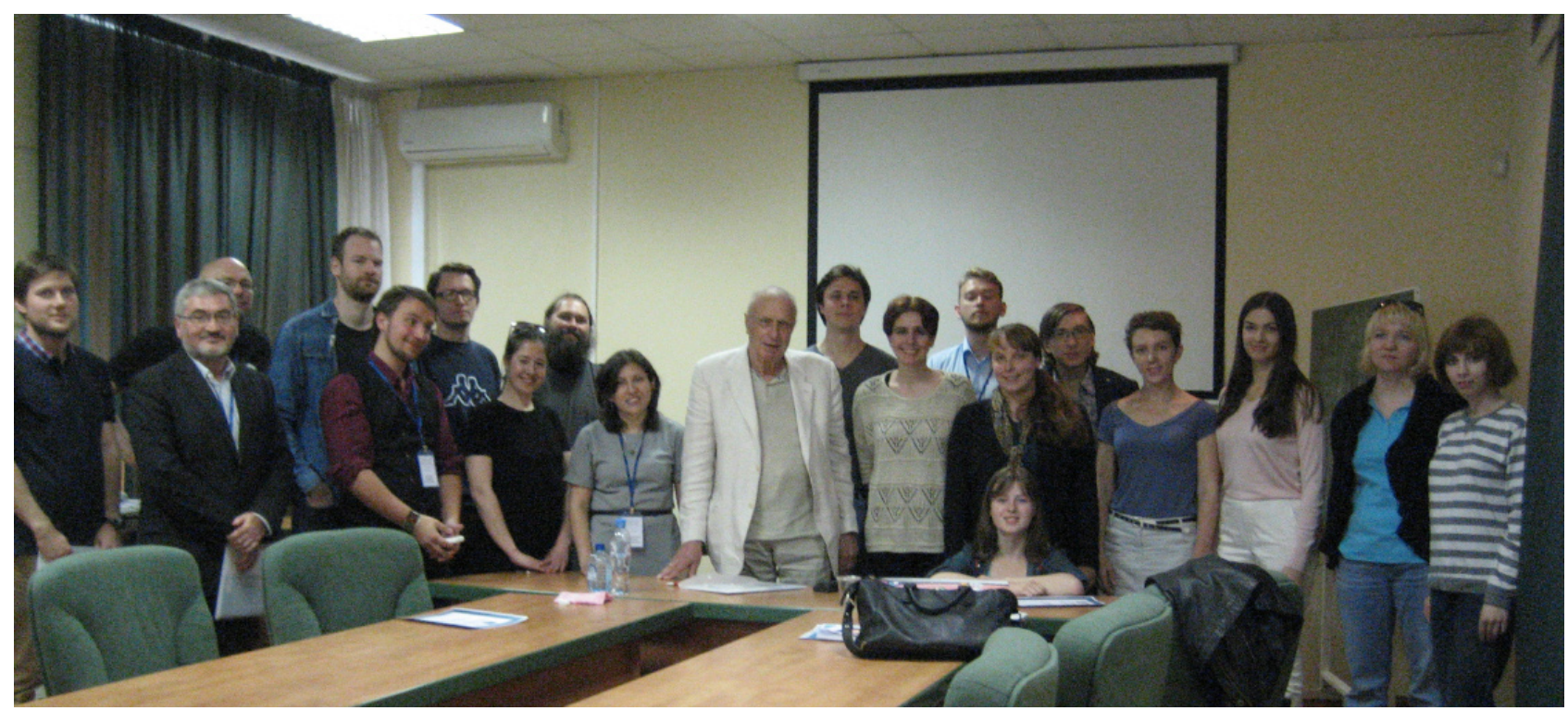

Это уже вторая школа молодых ученых, проводимая по данному проекту. Первая состоялась 19-23 мая 2016 г. под Белгородом и была посвящена теме «Концепции постчеловека в философии и технонауке». Был к школе издан соответствующий сборник (Концепции..., 2016). На первой школе уже было показано, что ответа на биотехнологическое улучшение человека нет, нужна площадка для обсуждения проблемы, а молодые ученые уже довольно скоро возьмут на себя труд более основательно разобраться в проблеме и примут ответственность за свой выбор не только для взбалмошного индивида, но и для человека и человечества в целом.

Новая школа углубила представления молодых ученых о проблеме «улучшения» человека. К началу школы также был издан сборник материалов, дающий представление о характере обсуждения (Биотехнологическое улучшение..., 2017). Вторая школа открылась выступлением Б. Г. Юдина, вводящего в предмет предстоящей научной дискуссии.

В лекциях заведующего сектором гуманитарных экспертиз и биотехнологии Института философии РАН П. Д. Тищенко «Будущее человеческой природы: переосмысляя концепцию Ю. Хабермаса», молодого ученого С. Ю. Шевченко «Эпистемологическая и антропологическая линии различения технологий «улучшения» человека» и др. тема раскрывалась преимущественно в философском ключе, в то время как в лекциидискуссии М. Кожевниковой «Концепт «межвидовости» и его этические последствия», лекциях О. В. Поповой «Нейроэтика и социальные проблемы когнитивного улучшения человека», Е. Г. Гребенщиковой «Нейроулучшение человека в нейро- и биоэтике», В. А. Лапшина «Проблематика изменения культурно-ценностного потенциала человека в условиях «информационного» и техногенного улучшения человека» и др. основной упор делался на том, что произойдет в обществе, если изменения челове- 


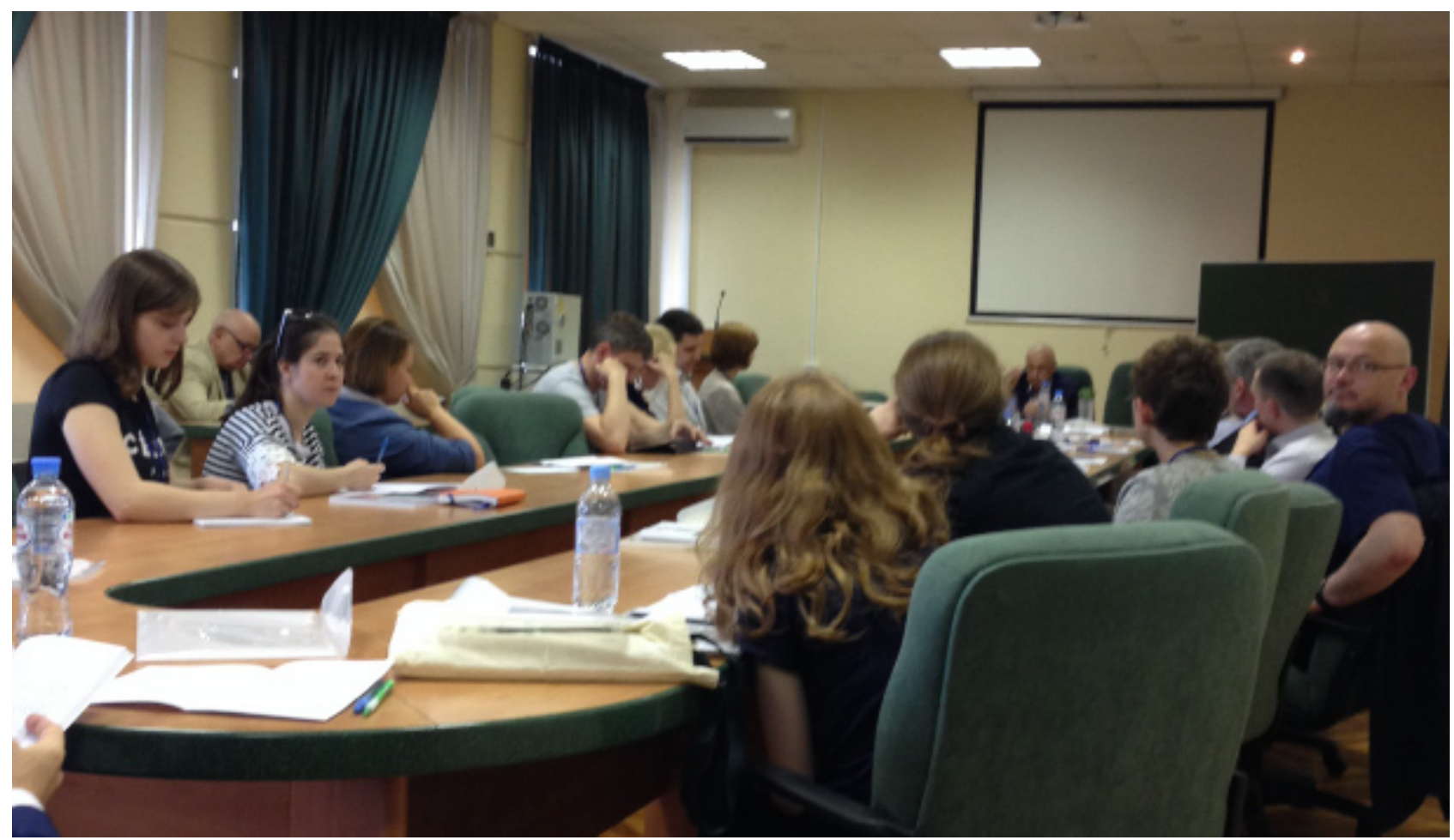

ка перейдут определенную природой границу. В этом ключе были выдержаны и выступления иностранных коллег (например, Я. Хартман говорил о в общественном здоровье изменится понимание ценностей, Л. Палаццани сосредоточилась на аргументах, выдвигаемых сторонниками и противниками «улучшения» человека в этической перспективе, в этом ключе интересны были лекции 3. Магича и И. Нейдерса, В. Дранзейко дал свою трактовку идентичности, которая будет присуща человеку по мере его «улучшения» и т. д.). Занятия в школе предполагали неоднозначность ответов, и, например, дискуссия Г. Б. Юдина и П. Д. Тищенко «Допинг: Нужно ли легализовать/Можно ли не легализовать?» не могла не вызвать живого интереса тех, кто наблюдал за ней.

В последний день состоялись фокус-группы участников школы молодых ученых по теме «Бессмертие как тезаурус» под общим патронажем директора Института фундаментальных и прикладных исследований МосГУ В. А. Лукова. Модераторами фокус-групп были его ученики Д. А. Тихомиров и О. И. Габа, видеосъемку на двух камерах осуществлял студент МосГУ Всеволод Дугин.

В каждой из групп определялись три вопроса, которые (как спорные) стоят перед молодыми учеными, участники аргументировали свои ответы на эти три вопроса, могли быть и разные ответы в одной группе. Среди прочего неясными пока остаются вопросы:

Могут ли биотехнологии дать бессмертие людям? (наротехнологии, минироботы, чистящие сосуды и т. д.)

В бессмертии ли заинтересованы люди? Или более долгой жизни? 


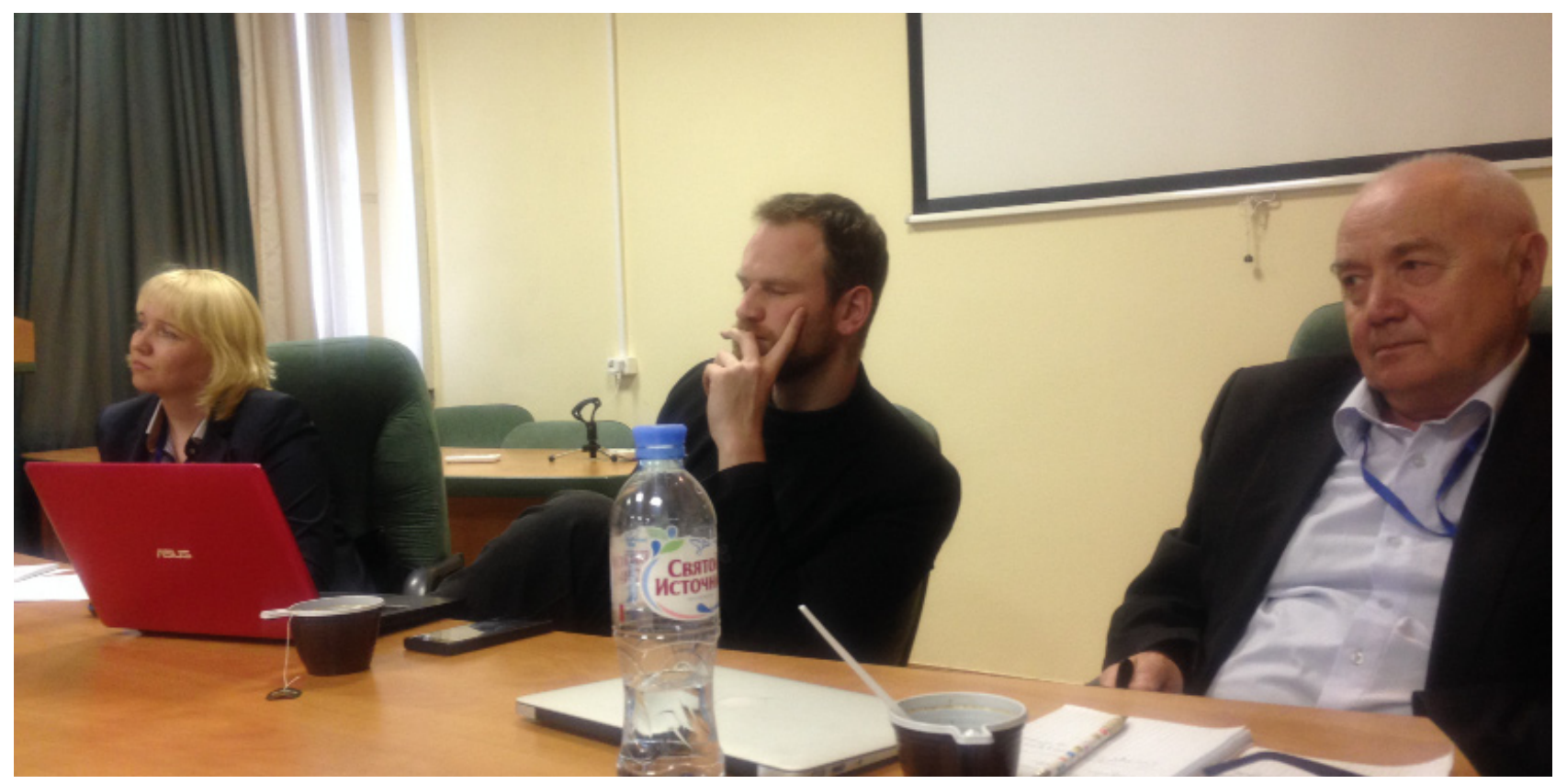

Насколько долгой?

В каком возрасте будут бессмертные - дети, молодежь, старики?

Если все бессмертны - как быть с народонаселением, мировой продовольственной проблемой, всеми другими глобальными проблемами человечества? Если не все, то кто? Как быть с идеей равенства?

«Улучшение» в смысле бессмертия задумывалось как способ перебраться людям на другие, в том числе далекие, планеты. Сейчас то же представление? Киборги - это «улучшение»?

«Улучшенные» люди сосуществуют с обычными, вытесняют их, вытесняются ими? Как происходит их взаимодействие?

Что меняется в обществе, если приходят бессмертные? Меняются ли границы полов, возрастов, деторождений, что происходит с ценностями, как с идентичностью, с социализацией, с отношениями народов?

Вот лишь некоторые вопросы из тех, на которые предстоит новому поколению дать ответы. До 1960-х годов всякие идеи о бессмертии, киборгах и т д. были чистой фантастикой, сегодня - экзотикой, завтра достижениями для избранных и общей темой. Переменятся и способы осмысления бессмертия в философии, социологии, психологии и т. д.

Школа молодых ученых может подсказать, в каких направлениях этот процесс пойдет.

\section{СПИСОК ЛИТЕРАТУРЫ}

Концепции постчеловека в философии и технонауке : материалы V Международной научной школы для молодежи (Белгород, 19-23 мая 2016 г.) (2016) / под ред. С. М. Климовой, А. Д. Майданского. Белгород : ИД «Белгород» НИУ «БелГУ». 245 с. 
Биотехнологическое улучшение человека как проблема социальногуманитарного знания : материалы школы молодых ученых. Московский гуманитарный университет, 26-30 июня 2017 г. (2017) / под ред. Б. Г. Юдина, О.В.Поповой. М. : Изд-во Моск. гуманит. ун-та. 208 с.

Дата поступления: 12.07.2017 г.

Луков Валерий Андреевич - доктор философских наук, профессор, директор Института фундаментальных и прикладных исследований Московского гуманитарного университета, заслуженный деятель науки Российской Федерации, Адрес: 111395, Россия, г. Москва, ул. Юности, д. 5. Тел.: +7 (499) 374-75-95. Эл. адрес: v-lukov@list.ru

Луков Сергей Валерьевич - кандидат социологических наук, начальник отдела прикладной социологии Центра социологии молодежи Московского гуманитарного университета. Адрес: 111395, Россия, г. Москва, ул. Юности, д. 5. Тел.: +7 (499) 374-75-95. Эл. адрес: sv-lukov@mail.ru

Lukov Valery Andreevich, Doctor of Philosophy, Professor, Director, Institute of Fundamental and Applied Studies, Moscow University for the Humanities; Honored Scientist of the Russian Federation. Postal address: 5, Yunosti St., Moscow, Russian Federation 111395. Tel.: +7 (499) 374-75-95. E-mail:v-lukov@list.ru

Lukov Sergei Valer'evich, Candidate of Sociology, Head, Department of Applied sociology, Centre for Sociology of Youth, Institute of Fundamental and Applied Studies, Moscow University for the Humanities. Postal address: 5, Yunosti St., Moscow, Russian Federation 111395. Tel.: +7 (499) 374-75-95. E-mail:sv-lukov@mail.ru

\section{Для цичтирования:}

Луков В. А., Луков С. В. Международная научная школа для молодежи «Биотехнологическое улучшение человека как проблема социально-гуманитарного знания» [Электронный ресурс] // Научные труды Московского гуманитарного университета. 2017, № 4.URL: http://journals.mosgu.ru/trudy/article/view/533 (дата обращения: дд.мм. гг.). DOI: $10.17805 /$ trudy.2017.4.10 